Thorax, 1977, 32, 691-696

\title{
Pulmonary hypertension in mitral valve disease: 56 surgical patients reviewed
}

\author{
J. M. MANNERS, J. L. MONRO, AND J. K. ROSS
}

From Wessex Cardiac and Thoracic Centre, Southampton Western Hospital, Southampton, UK

Manners, J. M., Monro, J. L., and Ross, J. K. (1977). Thorax, 32, 691-696. Pulmonary hypertension in mitral valve disease. A total of 392 patients have undergone prosthetic valve surgery including the mitral valve over a four-year period (1972-76). Of these patients 56 $(14 \%)$ had a pulmonary artery systolic pressure of $70 \mathrm{mmHg}$ or more during preoperative cardiac catheterisation and the hospital mortality of this group was $5 \cdot 4 \%$. Similarly, the hospital mortality of the remaining 336 patients with a pulmonary artery pressure below $70 \mathrm{mmHg}$ was $5.4 \%$. The presence of pulmonary hypertension in patients with valve disease including the mitral valve does not therefore indicate that the risk of dying in hospital as a consequence of corrective surgery is increased. The absence of a raised hospital mortality in this recent series may be attributed to improved surgical techniques and materials, while the use of droperidol and pentolinium which may reduce pulmonary vascular resistance as well as systemic resistance during surgery could be contributory.

Mitral valve replacement or repair are now routine operative procedures for patients with serious mitral valve disease and, with an operative mortality of $9 \%$ or less (Oparah et al., 1975; Fernandez et al., 1976; Mitha et al., 1976; Ionescu et al., 1977), provide the majority of these patients with an improved length and quality of life.

However, those patients who have developed severe pulmonary hypertension, although benefiting from mitral valve surgery, have been thought to withstand surgery less well (Emanuel and Ross, 1967; Najafi et al., 1969) and to have a higher operative mortality (Ward and Hancock, 1975). Kaul et al. (1976) have recently described a mortality of $30 \%$ in a series, collected over 10 years, of 30 patients with pulmonary hypertension undergoing mitral valve replacement, although there were no hospital deaths in the last 16 patients, while Ward and Hancock (1975) described a mortality of $56 \%$ in a small group of similar patients collected between 1961 and 1972. It would appear to be important to take the presence of pulmonary hypertension into consideration when assessing the risks of mitral valve surgery, and a review has therefore been made in the Wessex Cardiac Unit of patients with pulmonary hypertension who have undergone open mitral valve surgery.

\section{Material and method}

Records of the 1150 patients undergoing open heart procedures in a four-year period, 1972-76, were examined. Among those patients with acquired heart disease $(69 \%), 392$ who had at least the mitral valve replaced or reconstructed were studied. Of these patients, $56(14 \%)$ with mitral valve disease were found to have pulmonary systolic pressures of $70 \mathrm{mmHg}$ or more at the time of cardiac catheterisation, and this group of patients was reviewed.

The catheterisation was carried out prior to consideration for cardiac surgery. Premedication consisted of promethazine with papaveretum and hyoscine, or diamorphine and atropine; and the patients were supine and breathing air during the investigation. The relevant measurements of pulmonary and systemic pressures were made and the calculation of pulmonary vascular resistance (Wood, 1954) was carried out, using an assumed basal oxygen consumption. Arterial blood taken in the course of catheterisation was immediately analysed for oxygen and carbon dioxide tensions, using Radiometer $\mathrm{Po}_{2}$ and $\mathrm{PCO}_{2}$ electrodes, and latterly a Radiometer ABL 1.

At operation valve replacement was carried out using a Björk-Shiley or Starr-Edwards series 6120 prosthesis, and valve reconstruction was effected with a Carpentier ring. The ascending aorta was clamped during mitral valve procedures, the myocardial ischaemic periods not usually exceeding 20 minutes, with intermittent coronary perfusion.

The Temptrol, Harvey, or Galen bubble oxy- 
Table 1 Hospital mortality after mitral valve replacement

\begin{tabular}{|c|c|c|c|c|c|c|c|c|}
\hline \multirow[b]{4}{*}{ Valve replaced } & \multicolumn{8}{|c|}{ Pulmonary artery systolic pressure } \\
\hline & \multicolumn{5}{|c|}{$70 \mathrm{~mm} \mathrm{Hg}$ or more } & \multicolumn{3}{|c|}{ Less than $70 \mathrm{mmHg}$} \\
\hline & \multirow[b]{2}{*}{ Male } & \multirow[b]{2}{*}{ Female } & \multirow[b]{2}{*}{ Total } & \multicolumn{2}{|c|}{ Deaths } & \multirow[b]{2}{*}{ Total } & \multicolumn{2}{|c|}{ Deaths } \\
\hline & & & & No. & $\%$ & & No. & $\%$ \\
\hline Mitral & 9 & 24 & 33 & 2 & 6 & 199 & 9 & $4 \cdot 5$ \\
\hline Mitral and aortic & 5 & 7 & 12 & 0 & $\mathbf{0}$ & 107 & 8 & $7 \cdot 5$ \\
\hline Mitral and tricuspid & 2 & 5 & 7 & 0 & $\mathbf{0}$ & 8 & 0 & 0 \\
\hline Mitral, aortic and tricuspid & 1 & 3 & 4 & 1 & 25 & 22 & 1 & $4 \cdot 5$ \\
\hline Total & 17 & 39 & 56 & 3 & $5 \cdot 4$ & 336 & 18 & $5 \cdot 4$ \\
\hline
\end{tabular}

genator was used for normothermic bypass. It was primed and replenished with a Ringer lactate solution, unless the packed cell volume fell below $20 \%$ during bypass, when ACD or CPD preserved bank blood, 2-4 days old, was used.

Conventional anaesthesia consisted of papaveretum and hyoscine premedication, with induction using phenoperidine followed by thiopentone and pancuronium. Nitrous oxide was used to maintain anaesthesia, with $33 \%$ oxygen, and supplements of phenoperidine up to a total of $20 \mathrm{mg}$. Droperidol was used to maintain a radial artery systolic pressure below $140 \mathrm{mmHg}$ before bypass and a mean arterial pressure below $90 \mathrm{mmHg}$ during bypass at a flow of $2.41 \mathrm{~m}^{-2}$. If a maximum of $30 \mathrm{mg}$ droperidol failed to achieve this, pentolinium in increments of $0.5 \mathrm{mg}$ was given. These vasodilators were not used in the immediate postoperative period except when systemic systolic pressure exceeded $150 \mathrm{mmHg}$ after adequate intravenous sedation with diazepam and papaveretum.

After bypass isoprenaline, which has now been shown to produce pulmonary vasodilatation in animals (Mentzer et al., 1976), was the catecholamine generally used if inotropic agents were required. Occasionally adrenaline or dopamine were substituted despite their adverse effect on the pulmonary vascular resistance (Polumbo and Harrison, 1972) if the pressor response to isoprenaline was insufficient, if the heart rate exceeded $100 / \mathrm{min}$, or, in the case of dopamine, if the patient was oliguric with cold vasoconstricted extremities. The pulmonary artery pressure was not routinely monitored in the postoperative period although the right and left atrial and systemic pressures were measured.

After the operation all patients were ventilated with intermittent positive pressure ventilation using air and additional oxygen to produce an arterial $\mathrm{Po}_{2}$ of $10-14 \mathrm{kPa}(75-105 \mathrm{mmHg})$ and $\mathrm{PCO}_{2}$ of $4.5-6 \mathrm{kPa}(34-45 \mathrm{mmHg})$. When this regime was discontinued $40 \%$ oxygen was delivered by mask to the spontaneously breathing patient, and oxygen therapy was terminated when the $\mathrm{O}$ arterial $\mathrm{Po}_{2}$ was more than $10 \mathrm{kPa}(75 \mathrm{mmHg}) \stackrel{?}{工}$ or was found to be more than $8 \mathrm{kPa}(60 \mathrm{mmHg})$ after breathing air for 15 minutes.

\section{Results}

Over a four-year period, 56 patients with a pul- $\overrightarrow{0}$ monary systolic pressure of $70 \mathrm{mmHg}$ or more at.. the time of cardiac catheterisation underwent valve surgery, which included mitral valve replacement ( 55 patients) or reconstruction (1 patient), with a hospital mortality of $5.4 \%$ (Table 1). The mortality among 336 patients with a pulmonary $\mathbb{D}$ artery pressure below $70 \mathrm{mmHg}$ who also had at least the mitral valve replaced was similarly $5.4 \%$.윽

Of the hypertensive group, 33 patients had only the mitral valve replaced, with two deaths, 12 年 patients the aortic and mitral valves with no hospital deaths, and seven patients procedures to $\vec{\circ}$ the mitral and tricuspid valves with no deaths. In this latter group one patient had a mitral and tri- $-\dot{0}$ cuspid reconstruction with the use of Carpentier 3 rings, two patients had mitral valve replacement $\delta$ and tricuspid annuloplasty, and four patients mitral and tricuspid replacement. Four patientso underwent mitral, aortic, and tricuspid replacement with one hospital death.

Table 2 shows the relevant measurements and calculations at the time of cardiac catheterisation. ON

Table 2 Measurements during cardiac catheterisation

\begin{tabular}{|c|c|c|c|}
\hline & Mean & Range & $S D$ \\
\hline $\begin{array}{l}\text { Age } \\
\text { Pulmonary artery systolic pressure }\end{array}$ & 52 & $19-74$ & $11 \cdot 3$ \\
\hline $\begin{array}{l}\text { (mmHg) } \\
\text { Pulmonary artery mean pressure }\end{array}$ & 93 & $70-150$ & - \\
\hline (mmHg) & 57 & 40-90 & - \\
\hline Systemic systolic pressure (mmHg) & 116 & $80-180$ & $22 \cdot 1$ \\
\hline Systemic mean arterial pressure (mmHg) & 92 & $58-123$ & $15 \cdot 5$ \\
\hline Pulmonary/systemic systolic pressure \% & 80 & 46-157 & $20 \cdot 5$ \\
\hline Pulmonary/systemic mean pressure $\%$ & 62 & $31-111$ & $18 \cdot 4$ \\
\hline Pulmonary vascular resistance $/ \mathrm{m}^{-2}$ & $19 \cdot 2$ & $5-48$ & - \\
\hline Arterial oxygen tension $(\mathrm{kPa})$ & $7 \cdot 4$ & $9 \cdot 8-5 \cdot 3$ & 1.6 \\
\hline Arterial carbon dioxide tension $(\mathbf{k P a})$ & $5 \cdot 1$ & $3 \cdot 99-7 \cdot 71$ & 1.04 \\
\hline
\end{tabular}


During the catherisation these sedated and supine patients had a mean arterial oxygen tension of $7 \cdot 4 \mathrm{kPa}(55 \mathrm{mmHg})$ and arterial carbon dioxide tension of $5 \cdot 1 \mathrm{kPa}(38 \mathrm{mmHg})$.

Artificial ventilation in the postoperative period with air and added oxygen was given to all patients until the morning after the operation, but to only five patients $(9 \%)$ beyond this time. Three of these patients, one of whom subsequently died, were ventilated for a further 24 hours, while one patient required ventilation from day 3 after operation for two days. One other patient, whose subsequent death was attributed to Gram-negative septicaemia, was ventilated from day 6 until death on day 9.

Three patients in this group of 56 with pulmonary hypertension died in hospital. One woman aged 60 , who had aortic, mitral, and tricuspid valve replacements, died on day 9 from Gramnegative septicaemia, and her pulmonary and systolic pressures were $110 \mathrm{mmHg}$ at the time of catheterisation. One 51-year-old man, who required preoperative resuscitation and artificial ventilation before proceeding to mitral valve surgery, had both a pulmonary and systemic systolic pressure of $100 \mathrm{mmHg}$ and died in the operating room. One woman aged 74 years and weighing $33 \mathrm{~kg}$, who died four days after mitral valve replacement from a low cardiac output, had a preoperative pulmonary systolic pressure of $70 \mathrm{mmHg}$, which was $61 \%$ of systemic systolic pressure.

Table 3 shows the relevant catheterisation data for the 11 patients who had a tricuspid procedure compared with those for the 45 patients who did not. There is no significant difference between the two groups.

Table 3 Pressure measurements during cardiac catheterisation in patients who had tricuspid procedures and in patients who did not have tricuspid procedures

\begin{tabular}{lcc}
\hline & $\begin{array}{l}\text { Tricuspid } \\
\text { group }\end{array}$ & $\begin{array}{l}\text { Non-tricuspid } \\
\text { group }\end{array}$ \\
\hline Pulmonary artery systolic pressure (mmHg) & 96 & 92 \\
Pulmonary artery mean pressure (mmHg) & 61 & 56 \\
Systemic systolic pressure (mmHg) & 126 & 113 \\
Systemic mean pressure (mmHg) & 94 & 91 \\
Pulmonary/systemic systolic pressure \% & 75 & 81 \\
Pulmonary/systemic mean pressure \% & 65 & 63 \\
Pulmonary vascular resistance/m-2 & 22.7 & $18 \cdot 3$ \\
\hline
\end{tabular}

\section{Discussion}

In the past it has been stated that extreme elevation of the pulmonary vascular resistance increases the risks of bypass surgery (Cleland et al., 1969; Najafi et al., 1969) and that the long-term prog- nosis is poor (Barclay et al., 1972). Publications in the earlier days of bypass surgery had shown that the overall surgical mortality for mitral valve surgery had been higher in this group of patients (Nichols et al., 1964; Hamer et al., 1968). The present survey of mitral valve operations in a fouryear period has revealed that, despite the findings of severe pulmonary hypertension and a high pulmonary vascular resistance in 56 patients, the hospital mortality of $5.4 \%$ was the same as in a group of 336 consecutive patients whose pulmonary artery systolic pressure was less than $70 \mathrm{mmHg}$.

The present improved surgical results might be attributed to a spurious production of pulmonary hypertension in our patients at the time of cardiac catheterisation which did not occur in other series, to more favourable patient factors unrelated to pulmonary hypertension in this series, or to improvements in technique in the management of seriously ill patients.

During cardiac catheterisation a number of factors may influence pulmonary artery pressure and pulmonary vascular resistance (Smith and Hoffman, 1969) and these must be taken into account when assessing each patient. The present consensus is that hypoxia, hypercarbia, and catecholamines, together with reflex responses, produce vasoconstriction of lung arterioles and venules (Lee, 1971). In the group of patients we have studied the average arterial $\mathrm{Po}_{2}$ was $7.4 \mathrm{kPa}$ $(55 \mathrm{mmHg}$ ), which is higher than the level at which hypoxaemia was found to produce pulmonary vasoconstriction in animals (Rudolph and Yuan, 1966).

Arterial carbon dioxide tension was within normal limits in all but three patients and would therefore not have influenced the pulmonary circulation either by causing pulmonary vasoconstriction (Bergofsky et al., 1962) or by the increase in stroke volume and cardiac output (Prys-Roberts and Kelman, 1966) associated with hypercarbia.

The raised catecholamine level in patients with serious mitral valve disease (Chidsey et al., 1965) would seem to be one factor contributing to the production of pulmonary hypertension, merely reflecting the severity of the disease. The supine posture and therefore a further increase in lung blood-volume (Daly et al., 1964), already raised in mitral valve disease (Roy et al., 1965), was common to this group of patients and to those without pulmonary hypertension.

For these reasons the high pulmonary artery pressure in these patients seems to be related to the disease process and not simply a product of the circumstances of the cardiac catheterisation. 
Calculation of pulmonary vascular resistance using an assumed basal oxygen consumption introduces a wide margin of error, but, even if the actual oxygen consumption was as much as $30 \%$ above basal, the average resistance would still exceed 10 units $\mathrm{m}^{-2}$, while if the actual oxygen consumption was less than the assumed value the calculated resistance would be even greater.

Kirklin and Pacifico (1973) have drawn attention to the fact that in the presence of mitral incompetence the systolic wall tension is lower than would otherwise be the case. They have suggested that when there is no cardiac reserve the sudden loss of the ability of the left ventricular volume to decrease rapidly after valve replacement may contribute to a very low cardiac output. They therefore postulate that mitral valve replacement or repair might be made safer if it is advised before chronic congestive failure develops. The absence of failure as a favourable factor in this series was not apparent, but it is possible that there is a trend towards earlier operative treatment which is contributing towards lowering the mortality in patients formerly regarded as a high-risk group. The Figure illustrates that even in the patients with a very high pulmonary vascular resistance the risks of operation were not significantly greater than in the less severely affected patients.

There seems no doubt that surgical techniques and materials have improved in the last decade of cardiac surgery and that these are the major factors in the reduction of hospital mortality. The avoidance of bank blood primes for the heart-lung machine (Nahas et al., 1965), the use of filters in the bypass circuit (Hill et al., 1970), and the reduction of bank blood usage in the pcs:-perfusion period (Ross et al., 1976) may be significant in reducing the accumulation of debris in the pulmonary vascular bed, perhaps of particular importance in the presence of pulmonary hypertension.

The use of peripheral vasodilators or ganglionblocking drugs may also be advantageous during the postoperative period. The recent demonstration that pentolinium can reverse the pulmonary vasconstriction induced by nitrous oxide (Fahmy et al., 1976) suggests that these drugs could contribute to the successful management of patients with pulmonary hypertension. Droperidol, a drug with peripheral vasodilator activity, and pentolinium were used in this series for their systemic effect of reducing left ventricular afterload, but it is pertinent to note that droperidol reduces raised pulmonary vascular pressures (Macdonald et al., 1966) and that some ganglion-blocking agents have previously been shown to reduce pulmonary
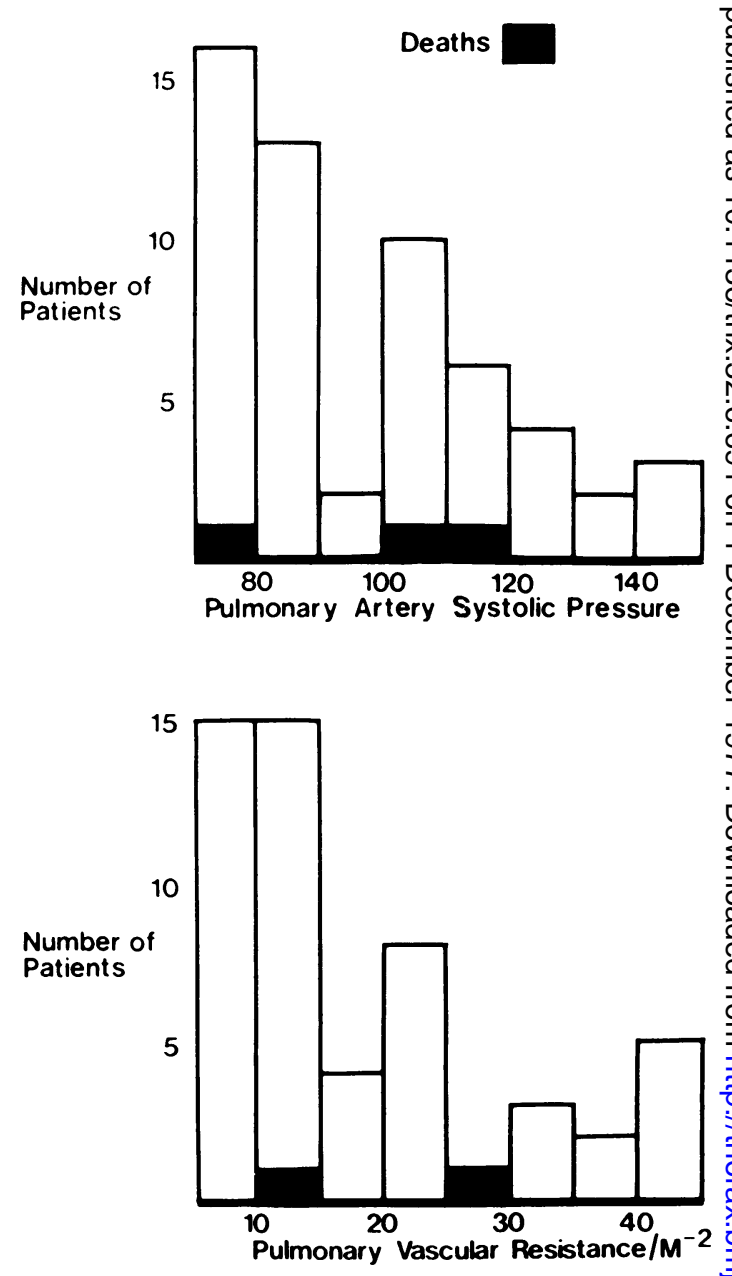

Note: No Wedge Pressure in 3 Patients

Figure Distribution of patients by pulmonary artery systolic pressure $(\mathrm{mmHg})$ and pulmonary vascular resistance.

vascular resistance in mitral valve disease (Scott et al., 1955; Balchum et al., 1957). The use of ô nitrous oxide in this series, despite its pulmonary 0 vasoconstrictor effect in the presence of mor-N phine (Lappas et al., 1975), does not appear to $\frac{\omega}{\sigma}$ have been detrimental, and a constrictor effect, if any, was perhaps offset by the use of phenoperidine, droperidol, and, less frequently, pentolinium.

The value of intermittent positive-pressure ven- 0 tilation (IPPV) for patients after open-heart sur-o gery, at a time when the cardiovascular system mayd be unstable, the residual effects of anaesthetic $\stackrel{\mathbb{D}}{0}$ drugs are present, respiratory work is increased $\cong$ (Wilson et al., 1973), and ventilation-perfusione ratios in the lungs may be abnormal (Laver et al., 
1970), is well established. Beyond 18 hours IPPV was discontinued in the majority of patients in this series as in other patients after mitral valve surgery, based on the principles described by Humphries et al. (1973), and this suggests that increases in pulmonary blood volume and water content were not important problems for most patients postoperatively.

The continuation of oxygen therapy in the postoperative period might be thought to influence the regression of pulmonary hypertension although there seems to be no specific evidence on this point. The mean preoperative arterial $\mathrm{Po}_{2}$ was only $7.4 \mathrm{kPa}(55 \mathrm{mmHg})$ but the improved haemodynamics which follow valve replacement would be expected to diminish pulmonary ventilationperfusion abnormalities, increase arterial oxygen tension, and therefore minimise hypoxaemic pulmonary vasoconstriction. However, Geha et al. (1966) found that, in a group of 10 patients undergoing mitral valve replacement, the mean arterial $\mathrm{PO}_{2}$ when breathing air had risen to only $9.7 \mathrm{kPa}$ $(73 \mathrm{mmHg}$ ) two weeks after operation compared with a preoperative value of $10 \cdot 1 \mathrm{kPa}(76 \mathrm{mmHg})$, while in the differing circumstances of non-cardiac thoracic surgery, arterial $\mathrm{Po}_{2}$ was below the preoperative level even 10 to 14 days after surgery (Knudsen, 1970; Manners and Crosse, 1976).

This series of patients has not been recatheterised to determine the effects of surgery on the pulmonary circulation but there is sufficient evidence to anticipate regression of severe pulmonary hypertension after successful isolated mitral valve replacement. Braunwald et al. (1965) described a marked decline in the pulmonary arterial or right ventricular systolic pressure after mitral valve replacement in every case in a series of 31 patients with pulmonary hypertension. Dalen et al. (1967) studied five patients after mitral valve replacement and found an early fall of pulmonary artery pressure from a preoperative mean of $71 \mathrm{mmHg}$ to $35 \mathrm{mmHg}$ and they concluded that the presence of extreme pulmonary vascular disease did not contraindicate surgical intervention. Nine patients with a pulmonary artery systolic pressure greater than $100 \mathrm{mmHg}$ were evaluated an average of 26 months after mitral valve replacement by Zener et al. (1972), when this pressure had fallen to a mean of $43 \mathrm{mmHg}$, while Kaul et al. (1976) also confirmed falls of similar magnitude 1-10 years after mitral valve replacement in all 21 survivors of their series.

\section{Conclusions}

The presence of pulmonary hypertension in patients with valve disease, including the mitral valve, does not indicate that the risk of dying in hospital as a consequence of corrective surgery is increased. Furthermore, there is sufficient evidence to anticipate that regression of severe pulmonary hypertension will take place after successful mitral valve replacement.

We are grateful to our cardiological colleagues, Drs. A. M. Johnson and N. Conway, for the cardiac catheterisation studies.

\section{References}

Balchum, O. J., Gensini, G., and Blount, S. G., Jr. (1957). The effect of hexamethonium upon the pulmonary vascular resistance in mitral stenosis. Journal of Laboratory and Clinical Medicine, 50, 186198.

Barclay, R. S., Reid, J. M., Stevenson, J. G., Welsh, T. M., and McSwan, N. (1972). Long-term follow up of mitral valve replacement with Starr-Edwards prosthesis. British Heart Journal, 34, 129-133.

Bergofsky, E. H., Lehr, D. E., and Fishman, A. P. (1962). The effect of changes in hydrogen ion concentration on the pulmonary circulation. Journal of Clinical Investigation, 41, 1492-1502.

Braunwald, E., Braunwald, N. S., Ross, J., Jr., and Morrow, A. G. (1965). Effects of mitral-valve replacement on the pulmonary vascular dynamics of patients with pulmonary hypertension. New England Journal of Medicine, 273, 509-514.

Chidsey, C. A., Braunwald, E., and Morrow, A. G. (1965). Catecholamine excretion and cardiac stores of norepinephrine in congestive heart failure. American Journal of Medicine, 39, 442-451.

Cleland, W., Goodwin, J., McDonald, L., and Ross, D. (1969). Medical and Surgical Cardiology, p. 867. Blackwell, Oxford.

Dalen, J. E., Matloff, J. M., Evans, G. L., Hoppin, F. G., Jr., Bhardwaj, P., Harken, D. E., and Dexter, L. (1967). Early reduction of pulmonary vascular resistance after mitral valve replacement. New England Journal of Medicine, 277, 387-398.

Daly, W. J., Giammona, S. T., Ross, J. C., and Feigenbaum, $H$. (1964). Effects of pulmonary vascular congestion on postural changes in the perfusion and filling of the pulmonary vascular bed. Journal of Clinical Investigation, 43, 68-76.

Emanuel, R., and Ross, K. (1967). Pulmonary hypertension in rheumatic heart disease. Progress in Cardiovascular Diseases, 9, 401-413.

Fahmy, N. R., Selwyn, A. S., Patel, D., and Lappas, D. G. (1976). Pulmonary vasomotor tone during general anesthesia and deliberate hypotension in man. Anesthesiology, 45, 3-13.

Fernandez, J., Morse, D., Spagna, P., Lemole, G., Gooch, A., Yang, S. S., and Maranhao, V. (1976). Results of mitral valve replacement with the Beall prosthesis in 209 patients. Journal of Thoracic and Cardiovascular Surgery, 71, 218-225. 
Geha, A. S., Sessler, A. D., and Kirklin, J. W. (1966). Arterial-alveolar oxygen gradients after open intracardiac surgery. Journal of Thoracic and Cardiovascular Surgery, 51, 609-615.

Hamer, J., Boulton, T., Fleming, J., Hayward, G. W., Hill, I. M., Monro, I., Simon, G., and Tubbs, C. S. (1968). Mitral valve replacement: long-term results, with particular reference to changes in pulmonary vascular resistance. Thorax, 23, 1-10.

Hill, J. D., Osborn, J. J., Swank, R. L., Aguilar, M. J., de Lanerolle, P., and Gerbode, F. (1970). Experience using a new dacron wool filter during extracorporeal circulation. Archives of Surgery, 101, 649-652.

Humphries, J. O., Gott, V. L., and Benson, D. W. (1973). Care of the patient undergoing valvular heart surgery. Progress in Cardiovascular Diseases, 15, $449-490$.

Ionescu, M. I., Tandon, A. P., Mary, D. A. S., and Abid, A. (1977). Heart valve replacement with the Ionescu-Shiley pericardial xenograft. Journal of Cardiovascular Surgery, 73, 31-42.

Kaul, T. K., Bain, W. H., Jones, J. V., Lorimer, A. R., Thomson, R. M., Turner, M. A., and Escarous, A. (1976). Mitral valve replacement in the presence of severe pulmonary hypertension. Thorax, 31, 332-336.

Kirklin, J. W., and Pacifico, A. D. (1973). Surgery for acquired valvular heart disease (Part 2). New England Journal of Medicine, 288, 194-199.

Knudsen, J. (1970). Duration of hypoxaemia after uncomplicated upper abdominal and thoraco-abdominal operations. Anaesthesia, 25, 372-377.

Lappas, D. G., Buckley, M. J., Laver, M. B., Daggett, W. M., and Lowenstein, E. (1975). Left ventricular performance and pulmonary circulation following addition of nitrous oxide to morphine during coronary-artery surgery. Anesthesiology, 43, 61-69.

Laver, M. B., Hallowell, P., and Goldblatt, A. (1970). Pulmonary dysfunction secondary to heart disease. Anesthesiology, 33, 161-192.

Lee, G. de J. (1971). Regulation of the pulmonary circulation. British Heart Journal, 33, Supplement, 15-26.

Macdonald, H. R., Braid, D. P., Stead, B. R., Crawford, I. C., and Taylor, S. H. (1966). Clinical and circulatory effects of neuroleptanalgesia with dehydrobenzperidol and phenoperidine. British Heart Journal, 28, 654-662.

Manners, J. M., and Crosse, M. M. (1976). Intermittent assisted ventilation. Anaesthesia, 31, 41-47.

Mentzer, R. M., Jr., Alegre, C. A., and Nolan, S. P. (1976). The effects of dopamine and isoproterenol on the pulmonary circulation. Journal of Thoracic and Cardiovascular Surgery, 71, 807-814.

Mitha, A. S., Matisonn, R. E., le Roux, B. T., and Chesler, E. (1976). Clinical experience with the Lillehei-Kaster cardiac valve prosthesis. Journal of Thoracic and Cardiovascular Surgery, 72, 401-407.

Nahas, R. A., Melrose, D. G., Sykes, M. K., and Robinson, B. (1965). Post-perfusion lung syndrome: effect of homologous blood. Lancet, 2, 254-256.
Najafi, H., Dye, W. S., Javid, H., Hunter, J. A. 듬 Ostermiller, W. E., Jr., and Julian, O. C. (1969). Mitral valve replacement. American Journal of Car $-\widehat{\overparen{ }}$ diology, 24, 386-392.

Nichols H. T., Raber, G. T., Blanco, G., Adam, A. ొి and Morse, D. P. (1964). Results of mitral valve sur gery in patients with severe pulmonary hypertension (Abstract). Circulation, 30, Supplement 3, 132-133. $\overrightarrow{\vec{\omega}}$ Oparah, S. S., Keefe, J. F., Ryan, T. J., and Berger, R. L. (1975). Mitral valve replacement with af turtleneck-disc prosthesis. Journal of Thoracic and Cardiovascular Surgery, 69, 568-574.

Polumbo, R. A., and Harrison, D. C. (1972) Response of the pulmonary circulation to dopamine infusion: in man (Abstract). Circulation, 45/46, Supplement 2, 56.

Prys-Roberts, C., and Kelman, G. R. (1966). Haemo-dynamic influences of graded hypercapnia in anaesthetized man. British Journal of Anaesthesia, 38,, 661-662.

Ross, J. K., Monro, J. L., Manners, J. M., Edwards, ర్ర J. C., Lewis, B., Hyde, I., Conway, N., and Johnson, $\stackrel{-}{-}$ A. M. (1976). Cardiac surgery in Wessex: review of $\overrightarrow{\mathscr{O}}_{\overrightarrow{0}}$ 1000 consecutive open-heart procedures. British Medical Journal, 2, 1485-1489.

Roy, S. B., Bhardwaj, P., and Bhatia, M. L. (1965). Pulmonary blood volume in mitral stenosis. British Medical Journal, 2, 1466-1469.

Rudolph, A. M., and Yuan, S. (1966). Response of the pulmonary vasculature to hypoxia and $\mathrm{H}+$ ion con-क्ष centration changes. Journal of Clinical Investigation, 45, 399-411.

Scott, R. C., Kaplan, S., and Stiles, W. J. (1955). Observations on the effect of tetraethylammonium chloride on the pulmonary vascular resistance in mitral stenosis. American Heart Journal, 50, 720 730.

Smith, N. T., and Hoffman, J. I. E. (1969). Evaluation® of the circulation-pulmonary and otherwise-ino man. Anesthesiology, 30, 589-592.

Ward, C., and Hancock, B. W. (1975). Extreme pulmonary hypertension caused by mitral valve disease. British Heart Journal, 37, 74-78.

Wilson, R. S., Sullivan, S. F., Malm, J. R., and Bow-은 man, F. O., Jr. (1973). The oxygen cost of breathing following anesthesia and cardiac surgery. Anesthesiology, 39, 387-393.

Wood, P. (1954). An appreciation of mitral stenosis or Part II: investigations and results. British Medicai Journal, 1, 1113-1124.

Zener, J. C., Hancock, E. W., Shumway, N. E., and ${ }_{0}^{\omega}$ Harrison, D. C. (1972). Regression of extreme pulmonary hypertension after mitral valve surgery.气 American Journal of Cardiology, 30, 820-826.

Requests for reprints to: Dr. J. M. Manners, Depart-更 ment of Anaesthetics, Southampton General Hospital, Shirley, Southampton SO9 4XY, UK. 